\title{
To Study Stomatal Conductance at Different Leaf Positions and Xylem Flow Rate at Different Depths in the Apple Branch
}

\author{
G. Nabi ${ }^{1}$, M. C. Trought ${ }^{2}$, R. Noor ${ }^{1}$ and A. Samad ${ }^{1}$ \\ ${ }^{1}$ Horticulture, Agricultural Research Institute, Tarnab, Peshawar , NWFP, Pakistan \\ ${ }^{2}$ Soil, Plant \& Ecological Sciences Division Lincoln University, Canterbury, New Zealand
}

\begin{abstract}
The influence of leaf position (age) on the shoot on stomatal conductance and depth on xylem flow rate in apples (Malus pumila) MM106 cv. Gala branches were studied at Lincoln University Canterbury, New Zealand. Leaf position on the shoot had significant effect on the stomatal conductance. Old leaves had a higher stomatal conductance $\left(\mathrm{g}_{\mathrm{g}}\right) 0.53$ (mol H $\mathrm{O} \mathrm{m}^{-2} \mathrm{~s}^{-1}$ day $\mathrm{O}^{-1}$ followed fully expanded new leaves with 0.48 (mol $\mathrm{H}_{2} \mathrm{O} \mathrm{m} \mathrm{m}^{-2} \mathrm{~s}^{-1}$ day ${ }^{-1}$ as compared to that for new (not fully expanded) leaves which was 0.20 (mol H$_{2} \mathrm{O} \mathrm{m}^{-2} \mathrm{~s}^{-1} \mathrm{day}^{-1}$. However, the apical positions exhibited rapid changes in $g_{8}$ while the intermediate leaves exhibited somewhat uniform changes in g. through out the day. A progressive decrease in xylem flow was measured across the branches of apple trees. The highest xylem flow was at $7.5 \mathrm{~mm}$ depth from the surface of bark.
\end{abstract}

Key words: Apple; Stomatal conductance; leaf position and xylem flow.

\section{Introduction}

The physiological activities of the healthy leaf may be influenced by three factors i.e. the age of the leaf, leaf position within the tree canopy and leaf position in different directions.

Leaf Age: The sequential development of leaves along a shoot results in basal leaves being chronologically older than that closer to the shoot apex. Alleweldt ot ol. (1982) reported that leaf age or position along the shoot has a significant effect on individual leaf photosynthesis rates. Kriedeman ot al. (1970) and Poni and Intrieri (1996) both agreed that in mature field grown vines the photosynthesis reached a maximum at 30 days after unfolding, and then declined with leaf age. Ferree et al. (1993) also found that shoot leaves from the terminal or mid areas of the shoot of apple trees had higher rate of net photosynthesis and transpiration than the basal leaves on the same shoot.

Leaf Position With in The Tree Canopy: Photosynthesis of apple leaves on fruiting spurs (with or without fruits) was $10-20 \%$ less than that of leaves on vegetative shoots or spurs. The exposure of leaves to more light intensity in a canopy is more important than the individual leaf performance Rom (1990). Leaves maintained at high light intensities exhibited a slower decline in photosynthesis and stomatal conductance than shaded leaves. At very low light intensity respiration will exceed photosynthesis (below the light compensation point) and plants may shed leaves. Inner canopy leaves eventually turn yollow and drop prematurely (Smart, 1985). Apical leaves are usually more exposed to ambient light, therefore receive more photosynthetically active radiation (PAR) (Smart, 1985). It dose not mean that the interior leaves with in the canopy do nothing, they may be exposed to intermittent direct exposure to the light for different duration during the day. But the question is what will be their response in term of stomatal conductance, if all the leaves on a shoot would expose equally to the direct sunlight?

Leaf position in different directiona: In field-grown cashew trees, stomatal conductance did not vary significantly with leaf direction or time of day, but photosynthesis were higher in leaves on the west side than in other directions. More over the maximum photosynthesis occurred in the leaves of the middle portion of the tree, rather than at the top or bottom (Palanisamy and Yadukumar, 1993). Jacob et al. (1990) reported that when sunflower (Helianthus annuus L.) and sorghum (Sorghum bicolor L. Moench) leaves were subjected to shading and the stomatal conductance was measured at $\mathbf{3 0}$ minute intervals. The speed and extent of reduction in stomatal conductance due to shading was greater in sorghum than sunflowers. When returned to normal light conditions, both species showed complete recovery of stomatal conductance. Leaf orientation of different plent species may be the adaptation of plant to different climatic conditions. Green et al. (1995) observed that in apple reflective ground covering could increase tree photosynthesis by about 32 percent, and transpiration by about 26 percent.

Xylem flow: Xylem flow rates in the field grown Prima apple tree were significantly correlated with irradiation and leaf area measurements (Ebert, 1995). Cambial activity is inhibited directly by water deficits when they become sever enough to dehydrate tissues containing mother cells and undifferentiated cambial derivatives and cause loss of turgor. The indirect effects of water deficits are on cambial activity are exerted by reduced synthesis and downward transport in the stem of carbohydrates are hormonal growth regulators (Withmore and Zahner, 1967).

Xylem flow and branch depth: Radial variation in sap flow velocity was observed across the sapwood with the lowest velocities at the center of the three-year-oid Eucelyptus globulus subsp. globutus trees (Zang-Dao Qun ot al., 1996). In case of pine (Pinus toeda), a $59 \%$ reduction in daily sap flow density from outer to inner sapwood was found. This could not be accounted for by a $3 \%$ drop in relative water content rather, an accompanying $\mathbf{9 \%}$ reduction in sapwood specific gravity indicated a transition between the depth intervals from mature to juvenile sapwood, and is the probable cause of the lower flow rate in the inner xylem of 


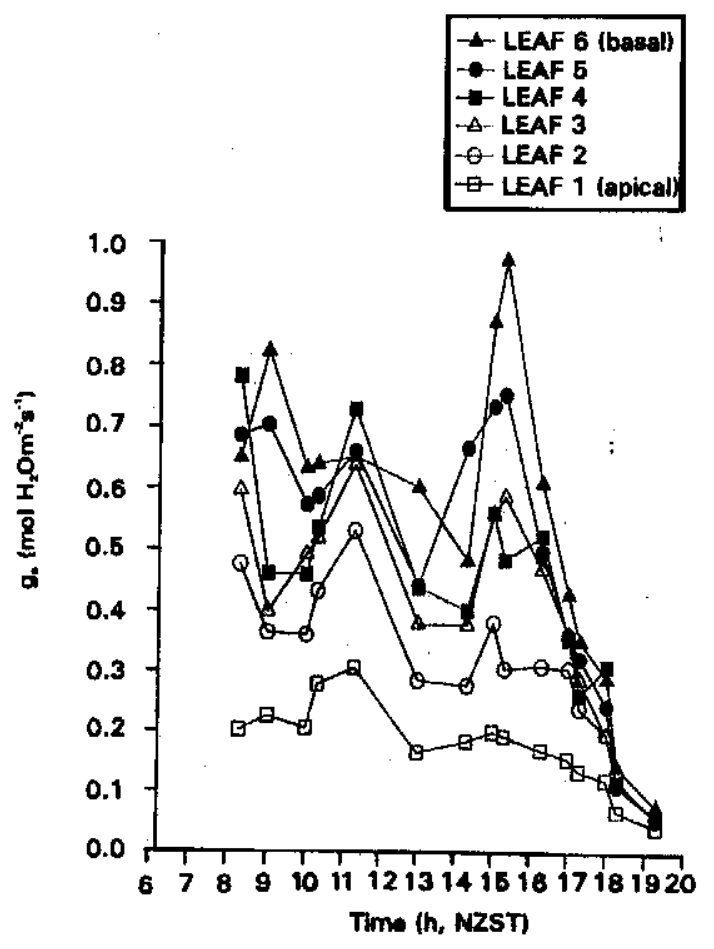

Fig 1: Influence of leaf position on stomatal conductance $\left(g_{0}\right)$ of Gala apple.

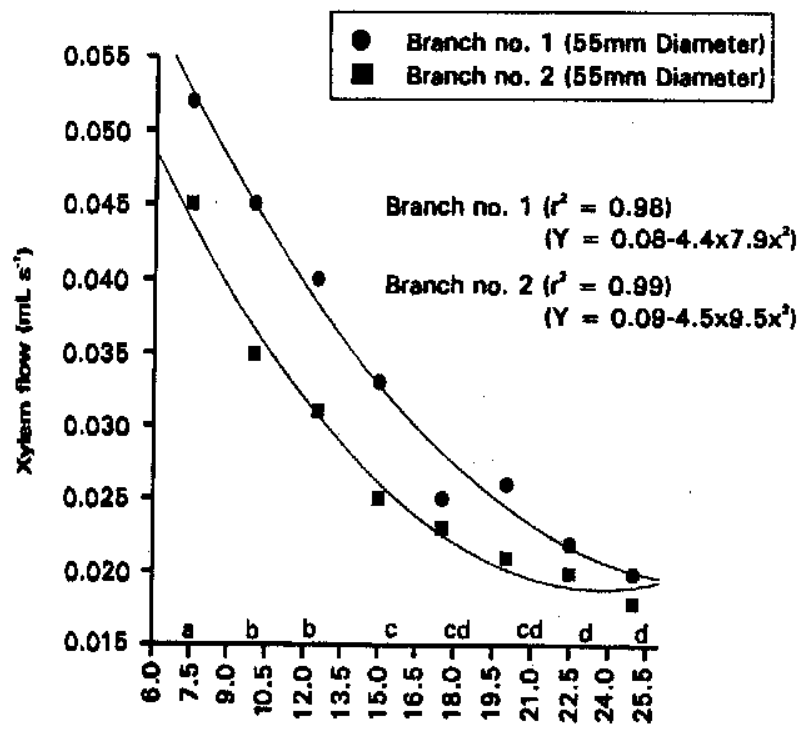

Distance from surface of the branch $(\mathrm{mm})$

Fig 2: Influence of different branch depths on the sylem flow rates of Gala apple grafted on MM106 rootstock. Means showing a common letter are not eignificantly at $P<0.05$ (Fisher LSD test).

plne (Phlllips et al., 1996). Navarro et al. (1992) injected PTS, marker of apoplastic flux, dye solutions and rubidium chloride into young olive trees, main scaffold branches or tree trunks moved mainly upward through the alder rings of the xylem, suggesting that uptake is directly controlled by the transpiration rate. A single injection was enough to distribute solutions in scaffold branches with a diameter of $8 \mathrm{~cm}$, but 2 injections were necessary for 17 $\mathrm{cm}$ diameter trunks. Which suggesting that xylem flow rate is more in the outer layer of sapwood or xylem vessels and lower in the inner or the centre layers of the sapwood. But again these depths are directly related to the age and diameter of the branch. So, keeping in view the above literature, two experiments were carried out at the same apple tree to investigate the influence of leaf position on a shoot and depth on xylem flow rate in apple branches. These studied will hopefully help those, who will have interest in measurements of stomatal conductance and xylem flow rates during their experiments.

\section{Materials and Methods}

Site and plant material: Experiments were conducted on 10 years old Gala apple on MM106 rootstock, trained using the horizontal Lincoln canopy training system at Horticultural Research Area, Lincoln University, Canterbury, Now

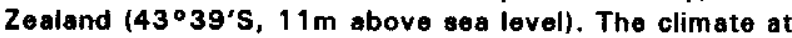
Lincoln is temperate, with average daily mean maximum and minimum temperatures of $16.7^{\circ} \mathrm{C}$ and $6.2^{\circ} \mathrm{C}$ respectively, and an average yearly rainfall of $666 \mathrm{~mm}$ (Nagle ot al., 1992). All experiments were undertaken in late Fobruary, 1997. Experiment was:

To find out the effect of apple leaf position on stomatal conductence: In this experiment on each side of the tree canopy five shoots were selected randomly, and the stomatal conductance of the six apical leaves on each shoot was measured using a Porometer, delte-T Model AP4. Data were collected approximately hourly from 8.00 to 19.30 (h, NZST) and analysed statistically using a fully factorial time series design.

To investigate the influence of depth on xylem flow rate in apple branches: In this case two branches wore selected on two different trees to investigate the xylem flow rate at different depths. Flow rates were measured by the method originally doveloped by Huber and Schmidt (1937) using Heat pulse logger model HP 8000 (Hort-Research, New Zesland). Two probes were inserted in to each branch. Thermistors were initially placed at depth of $25 \mathrm{~mm}$ from the surface of the branch. At 20 minute intervals the thermistors of one probe were withdrawn progressively to the outside of the branch and new measurements were taken at $2.5 \mathrm{~mm}$ increments. The remaining probe remained in the original location to act as a reference site. The flow rate at these different depths was normalized using the flow from the reference site. Data were analyeed statistically using a fully factorial time oeries design.

\section{Results}

The effect of apple leaf position on stomatal conductance: The oldest (basal) leaf on branch had a significantly higher ( $P<0.001)$ stomatal conductance $\left(g_{\varepsilon}\right)$ through out the day than the other leaf positions (Table 1). However, the apical positions exhibited rapid changes in $g_{\text {, through out the day }}$ Fig. 1. The $g_{9}$ of the apical leaf (position-1) was significantly lower $(P<0.001)$ than the other leaf positions through out the day, however the variation at the different times was less than that observed in the most busel leaves. The intermediate leaves exhibited a combination of the two

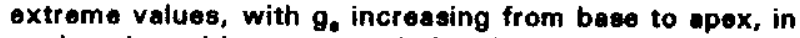
conjunction with greater variation during the day. 
Nabi ot al.: Stomatal conductance at different leaf positions and Xylem flow rate

Table 1: Influence of leaf position on stomatal conductance $\left(g_{s}\right)$.

\begin{tabular}{cc}
\hline Leaf position & Mean gs $\left(\mathrm{mol} \mathrm{H}_{2} \mathrm{O} \mathrm{m}^{-2} \mathrm{~s}^{-1} \mathrm{day}^{-1}\right.$ \\
\hline 1 (apical) & $0.20 \mathrm{o}$ \\
2 & $0.29 \mathrm{~d}$ \\
3 & $0.39 \mathrm{c}$ \\
4 & $0.41 \mathrm{bc}$ \\
5 & $0.48 \mathrm{ab}$ \\
6 (basal) & $0.53 \mathrm{a}$ \\
Significance & $\cdots$ \\
\hline
\end{tabular}

Mean' showing a common lotter are not significantly different at $P<0.05$. (Fisher LSD test). Significant $(P<0.001)$ denoted by $* * *$,

To investigate the influence of depth on xylem flow rate in apple branches: Xylem flow rates were measured on two branches of having $74 \mathrm{~mm}$ and $55 \mathrm{~mm}$ diameter. Both branches showed similar responses to flow at different depths. A quadratic regression provided a good fit to the data, with flow being greatest in the outer xylem vessels (Fig. 2). Attempts to measure flow at $5 \mathrm{~mm}$ depth failed probably because the thermistors were near to the bark and cambium layer of the branch. The flow rate was greater in the larger branch and was possibly a consequence of a higher leaf area on this branch. However leaf area was not measured.

\section{Discussion}

Leaf position or leaf age has a significant effect on physiological processes eg., stomatal conductance $\left(g_{2}\right)$ and photosynthesis (A). A close relationship between $A$ and $g_{8}$ has been reported by others (Chaves ot al., 1987; Jacobs et al., 1996; Cox and Jalliff, 1987; Johnson et al., 1987). The older leaves on the shoot had the highest mean $g_{8}$, similar to that reported for Acacia auriculiformis by Pathre et al. (1990). However, the rapid changes in $g_{\text {g }}$ observed on the basal leaves, possibly caused by shading from adjacent shoots.

A progressive decrease in xylem flow was measured across the branches of apple trees similar to that reported by Zang-Dao Qun ot al. (1996) on three year old Eucalyptus globulus subsp. globulus trees and Navrro et al. (1992) on olive trees. A reduction in the flow rate of the inner xylem of pine (Pinus treda) was also observed by Phillips et al. (1996) and they further reported that the probable cause of the low flow in the inner xylem was the result of a transition between juvenile and mature sapwood. The difference in xylem flow in different branches at similar depth may be difference in the age, growth or bark thickness of branches.

\section{References}

Alleweldt, G., R. Eibach and E. Ruhl, 1982. Investigations on gas-exchange in grapevine. 1 . Influence of temperature, leaf age and daytime on net photosynthesis and transpiration Vitis., 16:93-100.

Chaves, M. M., P. C. Harley, J. D. Tenhunen and $O$. L. Lange, 1987. Gas exchange studies in two Portuguese grapevine cultivars. Physiol. Plant, 70: 639-647.

Cox, W. J. and G. D. Jalliff, 1987. Crop water relations of sunflower and soybean under irrigated and dry land condition. Crop Sci., 27: 1185-1187.

Ebert, G., 1995. Assessment of xylem flow in fruit trees. Erwerbsobstbau, 37: 13-16.
Ferree, D. C., K. A. G. Clayton and B. Bishop, 1993. Influence of orchard management system on canopy composition, light distribution, net photosynthesis and transpiration of apple trees. J. Hortic. Sci., 68: 377392.

Green, S. R., K. G. Mcnaughton, D. H. Greer and D. J. Mcleod, 1995. Measurement of the increased PAR and net all-wave radiation absorption by an apple tree caused by applying a reflective ground covering. Agric. For Meteorol., 76: 163- 183.

Huber, B. and E. Schmidt, 1937. Eine Kompensations methode Zur thermoelektrischen messung langsamer saftstrome. Ber. Dt. Bot. Ges., 55: 514-529.

Jacob, J., T. J. Prasad and M. Udayakumar, 1990. On the differential stomatal behaviour in sunflower (Helianthus annuus L.) and sorghum (Sorghum bicolor L. Moench). Pla. Physiol. Biochem., New Delhi, 17: 62- 68.

Jacobs, C. M. J., B. J. J. M-van-den. Hurk and H. A. R-de, Bruin, 1996. Stomatal behaviour and photosynthetic rate of unstressed grapevines in semi-arid conditions. Agric. For. Meteorol., 80: 111-134.

Johnson, R. C., D. W. Mornhinweg, D. M. Ferris and J. J. Heitholt, 1987. Leaf photosynthesis and conductance of selected Triticum species at different water potentials. Pla. Physiol., 83: 1014-1017.

Kriedemann, P. E., W. M. Kliewer and J. M. Harris, 1970. Leaf age and photosynthesis in Vitis vinifera L. Vitis., 9: 97-104.

Nagle, W. G., R. J. Lucas and R. N. Rowe, 1992, Soil management for peach tree growth. New Zealand J. Crop Hortic. Sci., 20: 391:396.

Navarro, C., E. R. Fernandez and M. A. Benlloch, 1992. Low-pressure, trunk-injection method for introducing chemical formulations into olive trees. J. Am. Soc. Hortic. Sci., 117: 357-360.

Palanisamy, K. and N. Yadukumar, 1993. Photosynthesis in relation to radiation and leaf position in cashew trees. Photosynthetica, 29: 113-116.

Pathre, U. V., K. K. Singh and P. V. Sane, 1990. Gas exchange and stomatal conductance in Acacia auriculiformis: Effect of leaf position. Photosynthetica, 24: 151-154.

Phillips, N., R. Oren and R. Zimmermann, 1996. Radial patterns of xylem sap flow in non-, diffuse- and ringporous tree species. Pla. Cell Environ., 19: 983-990.

Poni, S. and C. Intrieri, 1996. Physiology of grape leaf ageing as related to improved canopy management and grape quality. Proceedings 9 th Australian Wine Industry Technical Conference, pp:113-122. Winetitles, Adelaide.

Rom, C. R., 1990. Light distribution in and photosynthesis of apple tree canopies. Acta Hortic., 279: 283-290.

Smart, R. E., 1985. Principles of grapevine canopy micro climate manipulation with implications for yield and quality. A review. Am. J. Enol. Vitic., 36: 230-239.

Whitmore, F. W. and R. Zahner, 1967. Evidence for a direct effect of water stress in the metabolism of cell walis in Pinus. For. Sci., 13: 397-400.

Zang, Dao-Qun., C. L. Beadle, D. A. White and D. O. Zang, 1996. Variation of sapflow velocity in Eucaiyptus globulus with position in sapwood and use of a correction coefficient. Tree Physiol., 16: 697-703. 